\title{
Commissioning Analysis and Improvement measures for Biomass Circulating Fluidized Bed Gasifier
}

\author{
Shan $\mathrm{Gu}^{1}$, Maosheng Liu ${ }^{2, *}$, Chunxiao $\mathrm{He}^{3}$, Jicheng Yang ${ }^{1}$ \\ ${ }^{1}$ Zhejiang University of Water Resources and Electric Power, Hangzhou 310018, China \\ ${ }^{2}$ China Jiliang University, Hangzhou 310018, China \\ ${ }^{3}$ Pyneo Co., Ltd., Hangzhou, Hangzhou 310012, China
}

\begin{abstract}
This paper presents the debugging test of biomass circulating fluidized bed gasifier in a rice mill factory of Jiangsu Province. The main debugging process of the gasifier system is reported. The typical problems of the gasifier system during the debugging period are analyzed, including the blockage of the primary cyclone separator, blockage of loop seal, bed inventory leakage of blast cap on air distribution plate, feeding tube coking, and large fluctuation of bed pressure. Reasonable improvement countermeasures and implementation plan is provided. The operation characteristics of the gasifier are preliminaries mastered through debugging, which provides reference for the operation and adjustment of the biomass circulating fluidized bed gasifier. These results provide certain guiding significance for the scale application of biomass circulating fluidized bed gasifier.
\end{abstract}

Key Words. Biomass Circulating Fluidized Bed Gasifier, Debugging Test.

\section{Introduction}

The development and utilization of biomass energy are of great significance to reduce greenhouse effect, air pollution and energy pressure. Biomass gasification is considered as one of the cleanest biomass utilization technologies. Due to its higher raw material adaptability, higher gas calorific value, higher production capacity, and wider adjustment range, the circulating fluidized bed (CFB) gasifier has a broader application prospect [1-2].

The commercial development of biomass CFB gasifier abroad is relatively mature. The leading countries in the field of biomass gasification abroad are Finland, Germany, the Netherland and so on [3-5]. At present, biomass gasification plants abroad are generally large in scale, high in automation and complex in process.

Research on biomass gasification technology in China started relatively late. After years of development, some progress has been made in the research and application of small gasification power generation, but it is mainly concentrated in fixed bed gasification, with problems such as low efficiency and small scale. At present, biomass circulating fluidized bed gasifier is still in the laboratory stage in China, and there are few reports of its industrial application.

The existing reports are basically applied to the gasification coupling large coal-fired power generation system, such as the $10.8 \times 10^{6} \mathrm{~W}$ biomass CFB gasification coupling power generation system of Guodian Changyuan Power Plant, and the $20 \times 10^{6} \mathrm{~W}$ biomass CFB gasification coupling system of Datang Changshan Thermal Power Plant [6]. There are few reports about the commissioning process and operational problems of biomass CFB gasifier.

This paper summarizes the commissioning and operation characteristics of $5 \mathrm{t} / \mathrm{h}$ biomass circulating fluidized bed gasifier in a rice plant in Jiangsu Province, which is aiming to provide reference for the large-scale application of this type of gasifier.

\section{Equipment Overview}

Biomass circulating fluidized bed gasifier is constructed in a rice plant in Jiangsu Province. The section size of dense phase zone in the lower part of gasifier is $1.2 \mathrm{~m} \times$ $1.2 \mathrm{~m}$, and the furnace wall tilts outward $30^{\circ}$ and gradually transits to the dilute phase zone. The section size of dilute phase zone is $1.8 \mathrm{~m} \times 1.8 \mathrm{~m}$, and the total height of gasifier is $18 \mathrm{~m}$. The schematic diagram of the CFB gasifier system are shown in Fig. 1, and main design parameters of gasifier are shown in Table 1. The gasifier adopts square furnace, which is composed of membrane water wall with external lining castable. The bottom of the furnace is provided with fluidized air chamber, and the ignition of light diesel oil under the bed is adopted. Biomass feeding system and quartz sand feeding system are set in front of the furnace. A two-stage adiabatic cyclone separator is arranged behind the furnace, and a loop seal is arranged under the primary cyclone separator

\footnotetext{
* Corresponding author: liums@cjlu.edu.cn
} 
to make the material flow back to the furnace. The high temperature ash recovery system is arranged under the secondary cyclone separator, and the high temperature ash is recycled after cooling. The high temperature gas extracted from the upper part of the secondary cyclone separator is fed into the gas steam boiler for combustion to produce saturated steam. Rice husk is used as raw material for the gasifier. Table 2 shows the proximate and ultimate analysis of rice husk. Quartz sand is used as bed inventory. Table 3 shows the physical parameters of quartz sand.

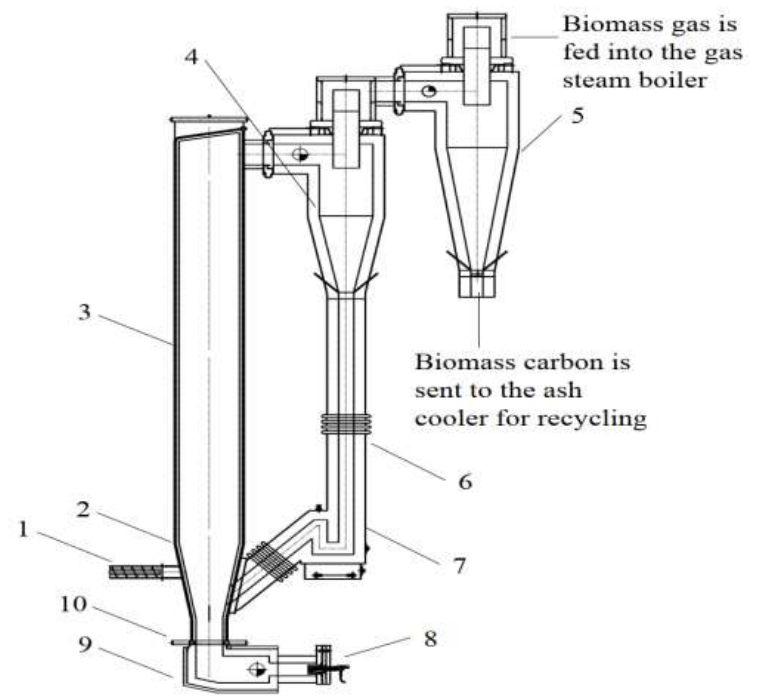

1-biomass feeder; 2-quartz sand feeder; 3-gasifier furnace chamber; 4-primary cyclone separator; 5secondary cyclone separator; 6-return pipe; 7-loop seal;

8-ignition burner; 9-fluidized air chamber; 10-air distributor

Figure 1. Schematic diagram of biomass circulating fluidized bed gasifier system

Table 1. Main design parameters of biomass circulating fluidized bed gasifier

\begin{tabular}{|c|c|}
\hline Item & Value \\
\hline $\begin{array}{l}\text { Gasification mode } \\
\text { Design fuel }\end{array}$ & $\begin{array}{l}\text { Circulating fluidized bed } \\
\text { Rice husk }\end{array}$ \\
\hline Fuel consumption & $\begin{array}{l}4.6 \mathrm{t} \cdot \mathrm{h}^{-1} \text { (equivalent to } 10 \% \text { water } \\
\text { content, design value, nameplate } \\
\text { consumption } 5 \mathrm{t} \cdot \mathrm{h}^{-1} \text { ) }\end{array}$ \\
\hline Ignition method & $\begin{array}{c}\text { Under-bed ignition by } 0 \# \text { light } \\
\text { diesel oil }\end{array}$ \\
\hline Bed temperature $/{ }^{\circ} \mathrm{C}$ & $700-800$ \\
\hline Bed pressure drop/Pa & $7500 \pm 100$ \\
\hline $\begin{array}{l}\text { Fluidizing velocity/ } \\
\qquad\left(\mathrm{m} \cdot \mathrm{s}^{-1}\right)\end{array}$ & $2-3$ \\
\hline $\begin{array}{l}\text { Gas production } \\
\text { rate } /\left(\mathrm{Nm}^{3} \cdot \mathrm{kg}^{-1}\right)\end{array}$ & $1.6-2.0$ \\
\hline Air equivalent ratio & $0.23-0.30$ \\
\hline $\begin{array}{c}\text { Gas calorific } \\
\text { value } /\left(\mathrm{kJ} \cdot \mathrm{Nm}^{-3}\right)\end{array}$ & $5000-6300$ \\
\hline Gas temperature $/{ }^{\circ} \mathrm{C}$ & $<800$ \\
\hline Carbon yield $/\left(\mathrm{t} \cdot \mathrm{h}^{-1}\right)$ & $0.5-0.8$ \\
\hline
\end{tabular}

Table 2. Proximate and ultimate analysis of rice husk

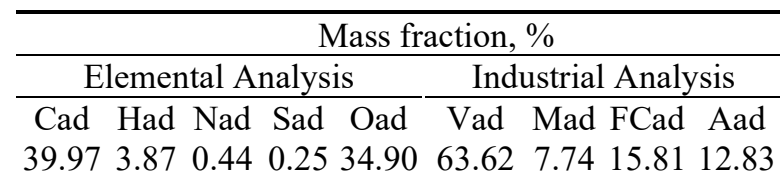

Table 3. Physical parameters of quartz sand

\begin{tabular}{cccccc}
\hline $\begin{array}{c}\text { Particle } \\
\text { size } / \mathrm{mm}\end{array}$ & $\begin{array}{c}\text { Average } \\
\text { particle } \\
\text { size } / \mathrm{mm}\end{array}$ & $\begin{array}{c}\text { True } \\
\text { density/ } \\
\left(\mathrm{kg} \cdot \mathrm{m}^{-3}\right)\end{array}$ & $\begin{array}{c}\text { Packing } \\
\text { density/ } \\
\left(\mathrm{kg} \cdot \mathrm{m}^{-3}\right)\end{array}$ & $\begin{array}{c}\text { Critical } \\
\text { fluidization } \\
\text { velocity of } \\
\text { cold } \\
\mathrm{state} /\left(\mathrm{m} \cdot \mathrm{s}^{-1}\right)\end{array}$ & $\begin{array}{c}\text { Particle } \\
\text { terminal } \\
\text { velocity } /\left(\mathrm{m} \cdot \mathrm{s}^{-}\right. \\
1\end{array}$ \\
\hline $0-2$ & 1.4 & 2721 & 1522 & 0.62 & 3.0 \\
\hline
\end{tabular}

\section{Debugging Process of Gasification System}

The debugging process of gasification system mainly includes three parts: monomer debugging, cold commissioning and hot state debugging. Monomer debugging includes the debugging of valve, bucket elevator, fan and other monomer debugging, such as baking boiler at low temperature and medium temperature, etc. Cold commissioning includes valve transmission and interlocking protection, air pressure test of gasifier and gas steam boiler, cold state aerodynamic field test, and assist system debugging, such as bed inventory system, dust discharge system, ignition system, air and flue gas system, etc. The cold aerodynamic field test is used to investigate the hydrodynamic characteristics of cold furnace and flue gas system. The test shall be conducted after the establishment of flue gas passageway from the gasifier and gas steam boiler furnace, through gas steam boiler outlet to draught fan inlet.

Hot state debugging includes hot state debugging of ignition system and dust discharge system, sodium hydroxide boiling furnace of gasifier and gas steam boiler, baking boiler of gasifier and gas steam boiler at high temperature, steam tightness and safety valve calibration, combustion adjustment test of gas steam boiler, unit startup and 168 hours trial run. Before the first ignition of the system, all auxiliary systems need to have operational conditions. And rice husk, fuel oil and other resources should be fully prepared and meet the requirements of start-up and trial run of the system.

\section{Main Problems and Treatment in Debugging}

\subsection{The Blockage of Primary Cyclone Separator}

In the initial stage of hot state debugging, when the gasifier was still in the combustion state, before turning to the gasification state, several successive blockages occurred in the primary cyclone separator. The separator began to block from the throat of the cone section. The conical section and straight pipe section of the separator had serious ash accumulation. There was obvious ash accumulation in the horizontal flow of the primary cyclone separator. 
On the one hand, the bed inventory of the gasifier was sea sand with high alkali metal content. When the temperature of the gasifier is higher than $700{ }^{\circ} \mathrm{C}$, massive quantity of alkali metal overflow from the bed inventory, resulting in the softening and aggregation of rice husk ash on the inlet flue of the primary separator and the outlet airway of the separator. The agglomerates fall off and block the throat of the separator. With the operation of the gasifier, more and more ash accumulates in the separator. The accumulated ash occurs secondary combustion with the increase of temperature, which makes the ash layer in the separator gradually firm. On the other hand, the exhaust hole in the return pipe was not opened according to the provision when baking boiler. This will result in the failure elimination of water vapor in the castable of the return pipe during the baking boiler. At the early stage of hot commissioning, the residual water vapor in the pipe rises to the primary cyclone separator, which makes the rice husk ash bond into blocks.

To solve this problem, the following measures can be adopted:

(1) Change the bed inventory from sea sand to quartz sand with particle size distribution range of $0-2 \mathrm{~mm}$, to avoid the generation of alkali metal in the bed inventory.

(2) A steam/compressed air blowing device is arranged at the bottom of the cyclone separator cone (see as Fig. 2), and clean the separator periodically. Compressed air is used to clean ash in direct combustion state of gasifier, and steam is used to clean ash in gasification state. A manhole door is provided near the cyclone separator throat. When the return material is found abnormal or cyclone separator is blocked or bridged, priority should be given to cleaning the separator. If this problem still can not be solved, then blowout the furnace and clean dust.

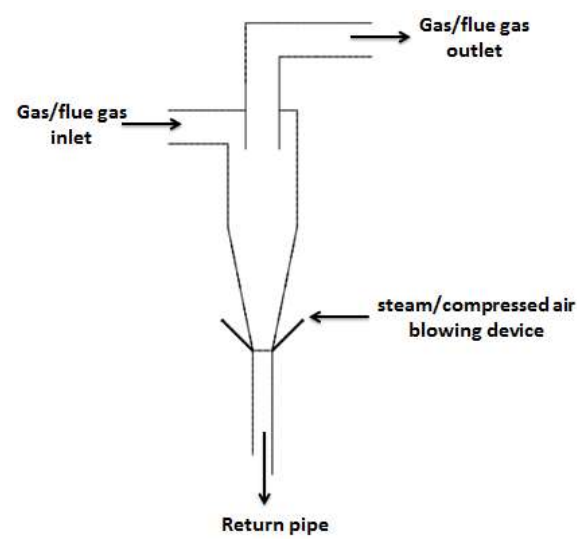

Figure 2. Example of steam/compressed air blowing device of primary cyclone separator

\subsection{The Blockage of Loop Seal}

After the gasifier was converted from combustion state to gasification state, the output of the feeder was increased to about $40 \%$, and the load of the gas steam boiler reached about $50 \%$. After running for a while, abnormal returning feed occurred. The loop seal under the primary separator of the gasifier was blocked by sintering ash, and the connection inclined pipe of loop seal was obviously agglomerated and blocked, as shown in Fig. 3.

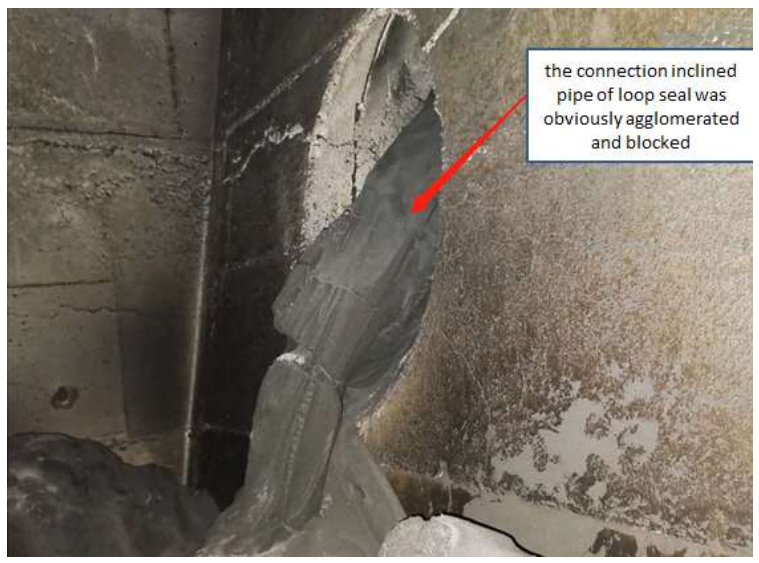

Figure 3. The blockage of loop seal

The reason for the blockage of the loop seal is the secondary combustion of high temperature ash and high temperature combustible gas when meeting the returning air, which makes the loop seal overtemperature and high temperature ash sintering [7]. When superheated steam is used as returning fluidizing medium, no ash coke was generated in the purging part of the returning steam. However, if the returning steam is injected too early or unevenly, there will still be coking and blockage of the loop seal. When the returning steam is injected too early, the hot steam encounters cold materials and precipitates water vapor, and rice husk ash is bonded into blocks under the action of water vapor. When the returning steam is injected unevenly, the rice husk ash will still reburn and caking at the position where the steam is not penetrated. To solve this problem, the following measures can be adopted:

(1) Air is still used as the fluidization feed-back medium in the gasifier during direct combustion, and the fluidization medium is switched to high temperature superheated steam into the loop seal before gasification. At the same time, maintain the material layer height of the loop seal, and control the appropriate returning air volume or steam volume.

(2) Adding steam nozzles to make injection uniforms. Six groups of steam nozzles are installed at about $200 \mathrm{~mm}$ above the loop seal caps, and the blowing angle and direction of steam nozzles are controlled. Insulate the steam pipeline, and change the steam hydrophobic position, to ensure that the returning fluidization medium is steam, rather than precipitated water vapor. Improve the pressure of returning steam, and keep the steam pressure at about 0.4-0.5 MPa.

\subsection{Bed Inventory Leakage of Blast Cap on Air Distribution Plate}

The blast cap on air distribution plate of the gasifier furnace adopted the mushroom caps with a diameter of 6 $\mathrm{mm}$. However, the bed inventory leakage of ignition air 
chamber in operation was more serious. In serious case, the bed inventory needed to be replenished more than three times per operation shift, and the furnace needed to be cleaned each shutdown.

Because of the form of direct blowing of the mushroom caps, when the bed pressure fluctuates in the operation of the gasifier, the fine rice husk ash and bed inventory will leak into the fluidization air chamber through the holes of the caps along with the fluctuation of the bed pressure. Moreover, it is inconvenient to repair and replace mushroom caps. The mushroom cap is an integrated structure. The lower part of the cap is welded on the air distribution plate and buried under the refractory materials. When repairing and replacing the caps, refractory materials must be knocked off, leading to the large maintenance cost.

The main measure adopted is to replace the mushroomshaped caps with the bell-shaped caps, the structure of which is shown in Fig. 4. The connecting pipe of bell caps extends into the top cover of the cap, and the hole of the cap does not directly contact with the bed inventory. Therefore, the leakage problem of mushroom caps can be solved. In addition, because the caps are not fixed in the refractory materials, when replacing the caps, only the top cover of the cap is removed without breaking the refractory materials, which saves time and reduces the maintenance cost [8].
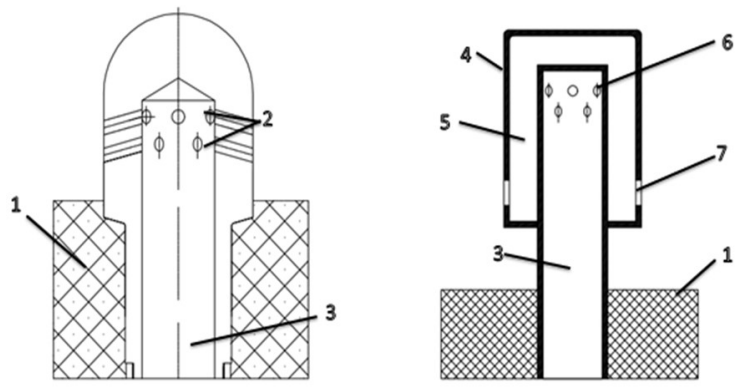

1-refractory material on air distribution plate; 2-hole of mushroom cap; 3- connecting pipe;

4-outer cover; 5-circumferential seam; 6-hole of inner core; 7 - hole of outer cover

Figure 4. Structure of blast cap (Left: mushroom-shaped cap, Right: bell-shaped cap )

\subsection{The Feeding Tube Coking}

During the initial heating stage of hot start-up of gasifier, coking phenomenon occurred several times at the end of feeding pipe near the gasifier wall.

The reason is that the negative pressure control of gasifier furnace is unstable, and the feeding port often runs under positive pressure, leading to the backflow of biomass combustible gas into the feeding pipeline. When condensable gas in the combustible biomass gas meets the cold pipe wall, it condenses and precipitates tar on the feeding pipe, resulting in partial fuel bonding in the pipe. In addition to $\mathrm{CO}, \mathrm{H}_{2}, \mathrm{CH}_{4}, \mathrm{CnHm}, \mathrm{CO}_{2}$ and other noncondensable gas, biomass gasification gas also contains some condensable components, commonly known as tar. Tar is gaseous at high temperature, mixed with product gas uniformly, and condensed at low temperature $(<$ $200{ }^{\circ} \mathrm{C}$ ), which can be easily bonded with water, coke, etc., and blocking pipeline [9]. Tar is inevitable during biomass gasification. With the increase of gasification temperature, tar production in gasification gas decreases rapidly [10]. Therefore, on the one hand, the negative pressure operation of gasifier should be controlled to prevent the reverse channeling of biomass combustible gas. On the other hand, the bed temperature should be strictly controlled to ensure that the gasification reaction is carried out at higher temperatures to reduce tar production. However, high gasification temperature should also be prevented from melting biomass ash and coking in the furnace.

To solve this problem, the following measures can be adopted:

(1) Ensure negative pressure operation of gasifier through operative adjustment. The negative pressure in the furnace at the feeding port should be controlled at about $-200 \mathrm{~Pa}$, and the temperature of the gasifier should be controlled at $700-800{ }^{\circ} \mathrm{C}$.

(2) Setting up a steam purging device at the end of the biomass feeder near the furnace wall, periodically purging the end of the feeder.

(3) Adding temperature measuring points in biomass feeding pipe to control feeding pipe temperature. When the temperature in the tube rises, it should be adjusted in time to reduce the negative pressure in the furnace and prevent the reverse channelling of biomass combustible gas.

(4) Controlling the quality of biomass fuel. It is required that the moisture content of the raw material is less than $15 \%$ and the particle size is less than $20 \mathrm{~mm}$, so as to prevent the blockage of the biomass feeding system due to the high moisture content and large particles.

\subsection{Large fluctuations of bed pressure}

In the initial stage of hot state debugging, the bed pressure of gasifier fluctuated greatly for many times. Taking the operation data on April 17, 2020 as an example: the gasifier ignited successfully at 13:28, and gasifier fuel oil was shutdown at 15:13. Bed pressure of gasifier fluctuated violently at 18:30, and stabilized slightly with the increase of bed inventory. Bed pressure of gasifier fluctuated again at 21:30, the bed pressure dropped from $7500 \mathrm{~Pa}$ to about $1900 \mathrm{~Pa}$, the highest bed temperature rose to about $1000{ }^{\circ} \mathrm{C}$, and the measures such as reducing fluidization air volume are ineffective. According to the program to stop the feeder at 23:30, the bed temperature dropped to about $600{ }^{\circ} \mathrm{C}$. The bed pressure returned to normal in $7500 \mathrm{~Pa}$ at 23:45.

The reason for the violent fluctuation of gasifier bed pressure is that the thickness of the bed inventory is too small and uneven feeding lead to uneven fluidization of bed surface and large swing of bed pressure. Moreover, the mushroom-type blast cap is used on the air distribution plate, with a small empty plate resistance. Under rated fluidization air volume, the empty plate resistance of the blast cap is only about $800 \mathrm{~Pa}$. When feeding or air supply is uneven, it is easy to cause uneven local fluidization of 
the air distribution plate. When the thickness of material layer increases, the resistance of bed layer increases, the fluidization of bed surface improves, and the fluctuation of bed pressure improves accordingly. The bed pressure fluctuates again, because the amount of returned material does not match the amount of feed, which leads to the imbalance and severe fluidization in some areas of the bed, and the bed pressure drops sharply. The bed pressure drops to about $1900 \mathrm{~Pa}$, the bed temperature rises to about $1000{ }^{\circ} \mathrm{C}$, because the furnace differential pressure is low, and the material circulation in the furnace is difficult to establish, resulting in high bed temperature. After stopping feeding, the gas precipitation in the furnace is reduced, resulting in the reducing of the amount of feed and bed temperature. Then the feed tends to be stable, and the bed pressure is restored to normal.

To solve this problem, the following measures can be adopted:

(1) Strengthen quality control of biomass fuel to avoid large impurities into the furnace. The height of the starting bed inventory of gasifier should be controlled at about $500 \mathrm{~mm}$, and the coarse particle size should be appropriately increased.

(2) Improve the operation adjustment level, so that the gasifier bed temperature is controlled at $700-800{ }^{\circ} \mathrm{C}$, and the fluidization air volume is controlled at about $2600-3000 \mathrm{Nm}^{3} / \mathrm{h}$. Control the feeding speed, the first feeding amount is controlled at about $40 \%$, and the gasifier is in the combustion state. To change the gasifier from the combustion state to the gasification state, the feed quantity increases rapidly from $40 \%$ to $70 \%$, and then the feed quantity increment is controlled at 2-4 \%. Increase fuel and air volume sequentially, and keep the bed pressure and bed temperature stability. Timely observer of bed temperature, bed pressure, return valve temperature and pressure changes, predict in advance, timely adjustment, and ensure the stability of gasifier gasification or combustion.

\section{Conclusion}

Through the implementation and operational adjustment of the above measures, the gasifier system has gradually been upgraded to full load operation. During the subsequent commissioning of the same type of biomass circulating fluidized bed gasifier, the following measures can be adopted to ensure the operation of gasifier under negative pressure: (1) selecting low-alkali metal and anticaking bed inventory; (2) using inert gas such as steam as fluidization medium; (3) controlling the quality of biomass fuel; (4) enhancing operation adjustment level of operators; (5) controlling of key parameters such as airfuel ratio, bed temperature, bed pressure, temperature variation rates of returning feed. This paper summarized commissioning experience of $5 \mathrm{t} / \mathrm{h}$ biomass circulating fluidized bed gasifier, and provided a series of improvement measures. The results of this paper have certain reference value for the operation and adjustment of biomass circulating fluidized bed gasifier.

\section{Acknowledgments}

This work was financially supported by Science and technology project of Water Resources Department of Zhejiang Province fund (Preparation of biomass carbon carrier for ammonia production catalyst by electroreduction of nitrate wastewater).

\section{References}

1. G. Mirmoshtaghi, J. Skvaril, P.E. Campana, et al. The influence of different parameters on biomass gasification in circulating fluidized bed gasifiers [J]. Energ Convers Manage. 126 (2016) 110-123

2. Z L Liu, W X Peng, et al. Circulating fluidized bed gasification of biomass for flexible end-use of syngas: a micro and nano scale study for production of biomethanol [J]. J Clean Prod, 129 (2016) 249-255.

3. D L Granatstein. Case study on Lahden Lampovoima gasification project, Kymijarvi Power Station, Lahti, Finland [R]. IEA Bioenergy: Task 36, 2002.

4. M Tiilikika, M Bolhar-Nordenkampf. Advanced gasification technologies for large scale energy production[C]. Power-Gen Europe 2014, Cologne, Germany, 2014. June 3-5

5. M Bolhar-Nordenkampf, J Isaksson. Operating experiences of large scale CFB-gasification plants for substitution of fossil fuels[C]. 24th European Biomass Conference and Exhibition, Amsterdam, the Netherlands, 2016, June 6-9.

6. S Gu, M S Liu, et al. Operational Characteristics of Biomass Circulating Fluidized Bed Gasifier [J]. Chem React Eng Technol (in Chinese), 37(2021),121-128+138.

7. H LWang. Cause Analysis of Slagging in CFB Boilers and Preventive Measures Thereof [J]. Therm Power Gener (in Chinese), 2007(2):28-30.

8. X Y Ji, X F Lu, et al. Design optimization of the bell type blast cap employed in small scale industrial circulating fluidized bed boilers $[\mathrm{J}]$. Adv Powder Technol, 25(2014) 281-291.

9. Reference to a chapter in an edited book: L L Ma, C $\mathrm{Z} \mathrm{Wu}, \mathrm{L}$ Sun. Biomass Gasification Technology and its Application [M]. Beijing: Chemical Industry Press, 2003

10. C Y Deng, W J Song, et al. Characteristics of Tar Thermal Cracking and Catalytic Conversion during Circulating Fluidized Bed Char Gasification [J]. Energ Fuel, 34(2020):142-149. 